Journal of Research in Technical Careers December 2018, Vol. 2, No. 2.

(C) Author(s)

\title{
Factors Impacting Former FFA Members' Decision to Discontinue FFA After High School
}

\author{
Danielle Eve-Marie Sanok ${ }^{\mathrm{a}}$, Christopher T. Stripling ${ }^{\mathrm{b}}$, Carrie A. Stephens ${ }^{\mathrm{b}}$, Andrew P. Griffith ${ }^{\mathrm{b}}$ \\ ${ }^{a}$ Knoxville Catholic High School, ${ }^{b}$ The University of Tennessee
}

The purpose of this study was to explore the factors impacting former National FFA Organization (FFA) members' decision to discontinue FFA membership after high school. Data were collected using focus groups. Data indicated areas of improvement for how to retain membership on the alumni level within colleges and other local FFA Alumni chapters. Participants noted a lack of advertising from the FFA during their high school experience, and this may partially explain why FFA loses a majority of its membership after high school. Additionally, advisors played an influential role in deciding not to continue with FFA, and participants expressed a need for career building opportunities for members as participants felt Collegiate FFA and the FFA Alumni lacked these opportunities. Other reasons participants' discontinued FFA involvement included lack of time, FFA burnout, and priority of FFA in their life. We recommend colleges and FFA consider implementing professional development to help advisors encourage participation in FFA beyond high school, increase advertising efforts about FFA opportunities, and publish tips, training, and information on how to start, manage, and maintain a successful alumni chapter. We also recommend local alumni chapters on college campuses consider increasing advertising and hosting career development opportunities. Moreover, as Collegiate FFA is no longer recognized as an official member type by the national organization, FFA should consider how to engage students who are involved at the collegiate level and are transitioning to FFA Alumni. Beyond the FFA, adult organizations should consider researching reasons for participation, since adults also seek learning opportunities, a sense of belonging, and achievement outside of the workplace.

Keywords: FFA, alumni, agricultural education

\section{Introduction}

Today's youth will meet the challenges of the future if formal and nonformal educational efforts prepare them for adult roles (National Research Council, 2012). The more educational experiences youth receive, the more likely they are to obtain desirable levels of career, health, and civic outcomes (National Research Council, 2012). With that in mind, youth clubs and organizations are important settings for creating positive influences and social contexts in youth personal development (Denault \& Poulin, 2009; Feinstein, Bynner, \& Duckworth, 2006). The act of participating in an organization is usually an instrument for stratifying individual or group goals, which are perceived to be desirable by participants (Berg, 2015; Douglah, 1970). People are attracted to and feel more inclined to be involved in activities that will satisfy personal needs such as achieving goals and opportunities provided by the organization (Berg, 2015; Douglah, 1970). According to Powell and Agnew (2007), success in any youth organization is being able to adapt and accommodate the different needs and interests of the involved youth.

The National Research Council (2009) suggested extracurricular activities are often more influential than formal instruction in career and life decision-making processes. Through these organizations, students gain a sense of responsibility, motivation, and influence (National Research Council, 2009). These activities and organizations also help students connect to issues related to food and agriculture (National Research Council, 2009). When students can collaborate inside and outside of the classroom with other students they are provided with more chances to interact with different individuals and backgrounds, leading to more diverse results than working individually (National Research Council, 2009).

Organizations such as the National FFA Organization (FFA) develop and foster their programs around high school youth development and preparing high school students for a career in agriculture (FFA, 2015). Between the years of 2015-2020, 35,400 students will graduate annually with a degree in 
agriculture, and there will be 57,900 jobs opening annually for those with a bachelor's degree or higher, making the demand for these jobs high (Goecker, Smith, Fernandez, Ali, \& Theller, 2015). In addition to degrees or content knowledge in agriculture, employers believe graduates need transferable twenty-first-century skills such as teamwork, communication, and leadership (National Research Council, 2009). According to the National Research Council (2009), FFA provides opportunities for youth to be "involved with an agriculture-focused national organization, to gain leadership skills, and to connect with scientists, practitioners, and other agriculture professionals” (p. 83).

At the time of this study, FFA had four membership types: active (secondary students), honorary, collegiate, and alumni. Today, active FFA membership is open to students grades seven through 12 enrolled in an agriculture course at their school (FFA, 2018a). To join as an active member, students pay the corresponding local, state, and national dues that are established at the local, state, and national levels. After high school, FFA provides a free five-year associate alumni membership in the FFA Alumni (FFA, 2018a). After this five-year period, national membership dues are required to retain alumni membership or one can pay annual membership dues to a local FFA Alumni chapter. Due to a constitutional amendment in 2017, collegiate is no longer recognized as an official type of membership. As a result, Collegiate FFA chapters are making a formal transition to FFA Alumni chapters on their college campus. Honorary FFA membership may be granted on the local, state, and national level and is for those "who are helping to advance agricultural education and the FFA and who have rendered outstanding service” (FFA, 2018b, p. 4).

FFA members have identified leadership development as one of the main reasons for becoming and continuing to be an FFA member (Rossetti, McCaslin, \& Gliem, 1996). The agriculture teacher is seen as a major influence on a student's personal leadership development (Feinstein et al., 2006; Greiman \& Addington, 2008). Similarly, Smith, Garton, and Kitchel (2007) discovered agricultural teachers and alumni often play a vital role for FFA enrollment and encouraging a positive FFA image. Also, FFA members identified leadership conferences, FFA contests, goal setting activities, and leadership positions as influential in developing their leadership potential (Ricketts \& Rudd, 2004). Furthermore, other reasons youth decide to join and participate in FFA are that FFA meets students' needs for increased self-esteem (Croom \& Flowers, 2001a; Croom \& Flowers, 2001b) and sense of belonging (Allen, Ricketts, \& Priest, 2007).

Additionally, researchers have found positive correlations between FFA participation and members' self-perception of leadership (Greiman \& Addington, 2008; Wingenbach \& Kahler, 1997). High self-efficacy can promote positive outcomes in self-motivation and pro-activeness among youth (McNally \& Harvey, 2001). Youth who have higher levels of self-efficacy are more likely to make informed decisions and persevere during difficult situations and tasks (Bandura, 1986; Tsang, Hui, \& Law, 2012). The more leadership experiences students participate in, the higher selfperception students have in skill areas such as communication, critical thinking, and leadership (Ricketts, 2005).

Rosch and Coers (2013) found on all levels of education, continuous leadership development contributes to a positive impact on the role of current and future leaders in society. Extracurricular activities provide numerous opportunities to apply classroom knowledge to real world settings (Allen et al., 2007; Montelongo, 2002; Rosch \& Coers, 2013). Allen et al. (2007) found throughout these extracurricular activities and leadership development programs within the FFA, there is great potential to produce greater levels of selfconfidence, self-motivation, and responsibility among participants. Furthermore, Montelongo (2002) found involvement in college student organizations and extracurricular activities benefits students beyond the classroom; participation increases students' sense of intellectual, social, and emotional self over time.

There are several positive aspects of joining the FFA. However, barriers exist as to why students do not stay involved in FFA beyond high school. Research on barriers have mostly been conducted at the high school level and include barriers such as agricultural teachers, the image of FFA and agriculture in general, former students, and friends (Talbert \& Balschweid, 2004). Research to identify what barriers exist on the collegiate and alumni levels is sparse (Allen, et al., 2007). According to Jim McCray (personal communication, January 29, 2015), Past National FFA Alumni President, FFA retains less than $40 \%$ of its current membership into alumni membership. Thus, this study seeks to shed light on the reasons why FFA members do not continue after high school, and what colleges and the National FFA Organization can do to increase overall collegiate and alumni membership.

\section{Theoretical Framework}

The Theory of Planned Behavior (Ajzen, 1991) served as the theoretical framework for this study, which postulates that perceived behavioral control, along with behavioral intent, can be used to predict behavioral outcomes and can help predict the outcomes of a student on the collegiate and alumni levels (Allen et al., 2007). According to Ajzen (1991), general attitudes and personality traits are implications for human behavior and have the potential to broaden influence. Additionally, intention plays a central and large role in how a certain behavior will be performed (Ajzen, 1991). Intentions are the motivational factors 
that can influence a behavior to occur, and they can indicate a person's work ethic, planning, and exertion to perform a certain behavior (Ajzen, 1991). Intentions are indicators of how hard a person is willing to work to perform the desired behavior; therefore, the stronger the intention to engage in the behavior, the more likely the performance of that desired outcome will be (Ajzen, 1991).

Ajzen (1991) found motivation and ability also have significant effects on the behavioral achievement of outcomes. The resources and available opportunities to a person will dictate the likelihood of the behavioral achievement (Ajzen, 1991). Motivation and ability is also influenced by a person's perceived behavioral control, which is how a person perceives the desired performing behavior (Ajzen, 1991). When perceived behavioral control is paired with behavioral intentions, the combination can predict behavioral achievement (Ajzen, 1991).

Additionally, Ajzen (1991) stated past behaviors can be possible indicators of future behaviors. Attitudes can be linked to past experiences, and attitudes are indicators of future behavior (Ajzen, 1991). Past behaviors are not a direct measure of a person's habit, but a reflection of factors that could help to determine a person's behavioral interest (Ajzen, 1991). Furthermore, Ajzen found each person will engage in their behavior of interest differently and will follow a different course of action based on their past experiences, attitudes, and beliefs.

Beyond Ajzen (1991), Terenzini and Reason's (2005) model of influences on student learning could further aid our understanding of how the college experience factors into active engagement in Collegiate FFA and the FFA Alumni (Smith et al., 2007). Terenzini and Reason stated that student success during their freshmen year was influenced by their pre-college characteristics, overall college experience, and the desired outcome from attending college. The most powerful of these three categories is pre-college characteristics and experiences as they include socioeconomic status, ability and performance, personal experiences, and academic preparation (Terenzini \& Reason, 2005). Moreover, Anderson and Kim (2009) found high school students perceived leadership development to be of high importance in preparation for college, involvement in other organizations, and their future careers. Additionally, students placed more importance on the areas and organizations in which they will receive more leadership education (Anderson \& Kim, 2009).

Beyond college and FFA, adult participation in organizations stems from adults needing to intrinsically serve a purpose in the community (Crowther, 2000; Douglah, 1970). Crowther (2000) found that adult participation in organizations within their communities is often recognized as a contributor for social change and reaffirms learning. Adults in Crowther's study viewed their participation in the community as self- determined, meaning their involvement was based on their own will and effort. Additionally, Crowther determined adult participation was a positive influence in adults' lives, but few adults recognize participation as such because participation involves transforming the unwilling into willing. Some adults viewed participation as unattractive or irrelevant, which was viewed as a barrier to participation, not resistance. Douglah (1970) agreed with this sentiment further stating participation from adults must serve a purpose and be ranked very high on the value scale.

\section{Purpose and Research Question}

The purpose of this study was to explore the factors impacting former FFA members' decision to discontinue FFA membership after high school. Therefore, the following research question guided this study: Why do some FFA members not continue FFA membership after high school?

\section{Methods}

Four researchers were involved in this study: an agricultural communication master's student, an associate professor of agricultural education, a professor of agricultural leadership and education, and an assistant professor of agricultural and resource economics. The master's student researcher has completed a bachelor's degree in agriculture education, continues to be active with the National FFA Organization, and is a former FFA State Officer. The associate professor of agricultural education and professor of agricultural leadership and education are former school-based agricultural education teachers and have recently published works in the areas of leadership, STEM, education, and college instruction. The assistant professor of agricultural and resource economics is an Extension specialist with a focus area of risk management in production agriculture and has limited 4-H and FFA experience. Collectively, we believe FFA members construct attitudes, beliefs and behaviors towards FFA involvement before they enter college. We believe intentions play a role in members' involvement in Collegiate FFA and the FFA Alumni. We also believe precollege characteristics such as sociodemographic traits, academic preparation, and personal and social experiences are contributing factors in an individual's decision regarding FFA membership. These beliefs influenced and provided the basis for the theoretical lens of this study.

A basic qualitative research design was used to "provide rich descriptive accounts targeted to understanding a phenomenon... or a particular point of view from the perspective of those involved" (Ary, Jacobs, Sorensen, \& Walker, 2014, p. 484). The target population for this study was former high school FFA members who chose to discontinue FFA membership after high school. The sampling frame chosen for this 
study was undergraduate students who were former high school FFA members attending the University of Tennessee. Subjects were selected for focus groups based on availability and the following predetermined selection criteria: (a) be a past FFA member in high school and (b) not a Collegiate FFA or FFA Alumni member. Participants were recruited for the study through advertising in University of Tennessee agricultural leadership, education and communications classes as well as through an online research participation portal set up by University of Tennessee. Two focus groups were conducted and were approximately 55 minutes in length. A semi-structured interview guide was used, which allowed for a better explanation of the phenomenon and participants experiences (Ary et al., 2014). Focus group one consisted of 11 participants, and the second focus group consisted seven participants. Thirteen of these 18 participants were female, and five were male. Nine participants were freshmen, four were juniors, and five were seniors. Nine participants were agricultural majors, and nine were non-agricultural majors.

The focus groups were audio-recorded and transcribed verbatim. The individual participants were assigned a student number (S1, S2, etc.) to protect their identities and distribute the research story (Bogdan \& Biklen, 2007). The use of participant codes is accepted practice in qualitative educational research (Ary et al., 2014) and is one way the researcher captures the participants' genuine thoughts and expressions without quantifying data elements used in illustrating the research story (Bogdan \& Biklen, 2007). Data were analyzed using the thematic analysis method, which allowed the researchers to curtail the data and "focus on repeated words of phrases...or evidence of answers to the research question/s which have been devised" (Grbich, 2007, p. 32). This allowed the data to "speak for themselves" (Grbich, 2007, p. 32), before the researchers have the opportunity to pre-assign themes. Furthermore, we used the block and file approach to conduct the thematic analysis (Grbich, 2007). After reading through the transcribed data multiple times, we individually organized the data into color-coded segments in order to categorize the data into themes. Next, we compared coding and came to a consensus on emergent themes present in the data. Finally, appropriate data were included as further evidence of each emergent theme.

According to Dooley (2007), "trustworthiness relates to the degree of confidence that the findings of the study represent the respondents and their context" (p. 38). Rigor and trustworthiness is obtained through the formulation of credibility, transferability, dependability and confirmability (Dooley, 2007; Lincoln \& Guba, 1985). Reflexivity, investigator triangulation of data analyses, and using member checking during focus groups were used to ensure credibility of researchers' observations, interpretations, and conclusions (Ary et al., 2014). Dependability, confirmability, and transferability were established by creating audit trails, literature comparisons, and detailed descriptions of methods (Ary et al., 2014). Furthermore, credibility and transferability were established using low-inference descriptors, using verbatim and direct quotes from participants, as well as peer debriefing and investigator triangulation in order to help fully understand participants' experiences (Ary et al., 2014). In order to establish trustworthiness, focus groups were audio-recorded and transcribed verbatim into Microsoft Word. Once the transcriptions were completed, audiorecordings were listened to for a second time for increased accuracy. A methodological limitation of this study was the data were collected from only students at the University of Tennessee, and their experiences may not be representative of other populations who have discontinued FFA membership after high school.

\section{Findings}

Data analysis revealed several themes to help explain why FFA members decide not to continue membership after high school. Common themes were the role of the FFA advisor; advertisement of Collegiate FFA and the FFA Alumni in high school; priority of FFA in members' lives; incentives to stay involved with the FFA; and participant perceptions of college, Collegiate FFA, and FFA Alumni.

Role of the Advisor. Participants expressed that their advisor played a key role in their overall FFA experience. Some participants described a positive experience with their advisor(s) (S3, S5, S7, S12, S16), while other participants noted a negative change in their overall FFA experience because of their advisor's influence (S2, S6, S10). Participants who had a positive experience with their advisor stated that their advisor was an influence to join and continue with their FFA involvement (S3, S5, S7, S12, S16). Some participants noted their advisor encouraged them to participate in Collegiate FFA and informed them about postsecondary opportunities (S2, S3, S6, S12, S13, S15). Participants that had a change in their FFA experience was due to one advisor leaving and a new advisor taking their place, expressing "I didn't know the other person, so I didn't end up doing anything, and I wasn't interested by the time I got to college to be in FFA" (S2). Participants (S10, S6) expressed they would not join the FFA Alumni because of the current advisor, "solely because I don't want to have to deal with the new advisor that came in my senior year. If it was still the advisor from my freshman through junior year, I would definitely be involved” (S6).

Advertisement of Collegiate FFA and the FFA Alumni in High School. When asked if participants had heard or seen advertising about Collegiate FFA and/or the FFA Alumni during their high school FFA 
experience, participants had varying responses. Some participants had heard about both organizations (S2, S3, S6, S8, S12), some participants were never informed (S1, S6, S7), other participants had heard it mentioned in passing by advisors (S9, S13, S15, S16), and other participants had never heard about either organization but noted their presence at various conventions (S5, S7, S10).

Participants who had heard about becoming involved in Collegiate FFA or the FFA Alumni heard it through their advisor (S2, S3, S6, S8, S12). If participants' agricultural teachers were actively involved with their alma mater's Collegiate FFA, they often "pushed" students to become involved (S3, S6). Participant 3 followed up by stating their agriculture teacher was "very involved in Collegiate FFA, so she would always tell us about how much stuff they did and how it can be hard with class," which made her question the time commitment of being involved in college. When asked how this affected their decision making process, Participant 3 noted it was "overkill” while Participant 6 stated "it just kind of in one ear out the other."

Some participants noted while no one verbalized continuing their FFA experience past high school, they knew there were opportunities with FFA past high school because of varying presences at state and national conventions. Participants (S10, S5) said the state and national officers presence informed them there might be opportunities for FFA past high school: "seeing the state officers and the national officers, you can tell that they are not high school students...so you kind of get from them that there is a collegiate level, it was just never described in detail” (S10). Participant 7 also remembered seeing Collegiate FFA booths at conventions.

Participants were asked questions on what would influence them to become involved with Collegiate FFA and the FFA Alumni and results varied. Participants expressed they would like to see Collegiate FFA reach out more on campus (S1, S5, S6, S9, S10, $\mathrm{S} 11)$ as "FFA is just a ghost" (S10) on campus. Participant 1 stated they had been on campus for two years and "I don't think I have ever seen a sign here," with Participant 5 agreeing, "I think that would help a lot if they did promote it a little bit more. Not just on the ag campus, but on the main campus." Participant 16 thought that main campus advertising was important as there were:

FFA members in high school [that] didn't come from farms, didn't have an ag background and [were] probably not going to major in ag. So there are probably lots of FFA or ex FFA members that go to the main campus.... You don't have to be an ag major to be in FFA.

Some participants stated they intended to become involved with Collegiate FFA, but did not know how. Participant 13 expressed, "I was really excited they had an FFA here, I just didn't know who to go to or how to get involved because I had never heard anything .... now I know, but it is a little too late.” Participants suggested posters be put up around campus (S1, S9, S10, S17, S16, S18) and suggested emails would be a beneficial way to promote the organization/get the word out about Collegiate FFA (S1, S3, S10, S16). Finally, participants suggested Collegiate FFA could be more involved with the community by having booths at sporting events and conducting volunteer service opportunities in order to promote the organization (S13, S16, S17).

Since most participants did not hear much about FFA opportunities past high school, participants were asked if their decision to join would have been impacted differently if someone had discussed Collegiate FFA or FFA Alumni opportunities with them and results varied. Four participants (S13, S14, S15, S16) said they would join Collegiate FFA if someone had discussed these opportunities with them, but also, only if there was enough time. Two participants were undecided, stating they might join (S3, S10). The rest of the participants (S1, S2, S7, S8, S9, S17) would not join even if someone had discussed opportunities with them in high school.

Priority of FFA in Members' Lives. Participants communicated once they got to college, their priorities changed from high school, including how FFA was prioritized in their life. When thinking back to how they prioritized FFA in high school and the reasons they joined, results varied. Participants indicated they joined because of family influences (S1, S2, S3, S7, S9, S10), friends (S4, S6, S8, S9, S13, S14, S16, S18), FFA's good reputation (S12, S15, S17), an advisor (S5, S12, S16), and one joined because FFA looked good on college applications (S4). Participants continued to stay involved in high school because of state and national conventions (S1, S3, S7, S10), making friends (S4, S5, S9, S10, S15), meeting new people outside their chapter (S7, S10), career development events (S1, S6, S7, S13, S15, S16, S18), and meetings (S2).

Many participants stated time commitment (S1, S2, S3, S7, S10, S12, S14, S15, S17) and worrying they would "spread myself too thin" (S12) was the main reason they decided to discontinue with their FFA experience past high school. Participant 14 stated living off campus also makes it difficult to attend meetings: "I am not going to drive 30-40 minutes back to campus for a meeting that is going to last 30 minutes.” Other participants expressed they did not believe they could balance their time between schoolwork, Greek life, and being in Collegiate FFA (S1, S2, S3, S4, S8, S9), thus putting Greek life involvement before FFA involvement.

Participants continually shared they wanted to be involved in organizations that were "more career focused" and if they were a non-agriculture major, there was less incentive to become involved in Collegiate FFA (S1, S2, S3, S4, S5, S7, S10). Participants 
expressed joining more career focused organizations or Greek life as something new and different. Participant 5 expressed, "if it's not really for your major, then you're not really thinking about it," and they were going to be involved in an organization that was going to further career goals and expectations. Seven participants conveyed difficulty in finding initiative to come over to the agricultural campus for Collegiate FFA if they were a non-agriculture major and Collegiate FFA was out of sight and out of mind.

Participants also stated that once they got to college, they were looking for something "new and different" (S7) and did not want to continue with their FFA experience. Participant 6 stated,

My FFA experience all through high school was really great and I really enjoyed it and I learned a lot of things that I wouldn't trade for the world but it was just, I knew that it was time for that experience to be over and to have new experiences that were different.

Participants stated that they were looking for "something outside of my box and my comfort zone" (S1, S2, S7) once they got to college, so they decided not to continue with their FFA experience. Participants also experienced "FFA burnout" (S4, S6, S7, S10) from their involvement in high school and were "over it" (S10) by the time they entered college.

Incentives to Stay Involved with the FFA. Some participants felt that there was no incentive to join FFA in college because of the structure of other collegiate organizations on campus (S13, S14, S15, S16, S17). Participants expressed that in high school, FFA was the "house" (S14) for many of the current clubs on campus such as horse judging, livestock judging, soils, and so forth (S14, S15, S16). Participant 17 stated that different clubs on campus take away a piece of what FFA was in high school stating,

FFA did you know horse judging, chicken judging, you know dairy judging, everything else, here [college] it seems like each thing has its own club, so you don't necessarily have to be involved in FFA to do poultry or horse judging.... So what is the incentive to join FFA if you can do that one thing that you want to do with one of the other clubs?

Participants also expressed their feeling that they could only be involved with one organization on campus because of time commitment (S13, S14, S15, S16) and expressed "to get that membership up, pull the contests in under one roof" (S15) as when there are numerous clubs that are "separated and divided I think it takes away from Collegiate FFA” (S15).

When asked if participants would join the FFA Alumni after college, participant results varied from yes (S7, S13, S14, S15, S16), no (S1, S2, S4, S6, S9, S10, S17, S18) to unsure, because their local chapter does not have an alumni organization (S3, S5, S8, S10, S11). Participants who expressed that they would not be involved with the FFA Alumni had varying reasons for discontinuing with their FFA experience. Once interest in high school was lost, there was no incentive to join the FFA Alumni (S1, S2, S4, S9). Participant 18 stated that being involved in the FFA Alumni would be "a step opposite of where I am going” and would not help with future career goals and plans. Participant 6 stated that they would not be involved with the FFA Alumni because of the current advisor stating,

I am currently not interested in being a part of it solely because I don't want to have to deal with the new advisor that came in my senior year...I am not interested in having to deal with him anymore.

Participant Perceptions of College, Collegiate FFA, and FFA Alumni. Participants expressed that they never see anything related to Collegiate FFA on campus (S1, S2, S3, S6, S7, S9, S10, S11, S12, S14), indicating if participants are not exposed to material related to FFA, they are not going to obtain any further knowledge, understanding or information related to FFA. Four participants heard about the FFA Alumni Convention and no participants had heard about FFA New Century Farmer, but participants expressed wanting to be involved in organizations that helped to further their careers, which these conferences in part, aim to achieve. Participants were also confused to the role of Collegiate FFA and the FFA Alumni. Some participants believed that Collegiate FFA was an organization directed towards high schools with less opportunities for alumni (S16), some believed the role was to help out with high school events (S13, S15, S16, S18), some wanted to still participate in contests (S16, S17), while the remaining participants made no indication of knowing what FFA did or was supposed to do past high school.

Nine participants were freshmen and perceived college to be harder than high school. Thus participants were scared to be too involved because they did not know how much time they could commit to Collegiate FFA and did not get involved past high school because of the "time commitment" (S1, S2, S7, S12, S14, S15, S17) and the fear of Collegiate FFA taking away from their focus on schoolwork (S1, S2, S3, S10, S12).

\section{Conclusions and Recommendations}

Overall, former FFA members in this study do not continue with their FFA experience because of: (a) the role of the FFA advisor, (b) advertisement of Collegiate FFA and the FFA Alumni in high school, (c) priority of FFA in members' lives, (d) incentives to stay involved with the FFA, and (e) participant perceptions of college, Collegiate FFA, and FFA Alumni. Ajzen (1991) found attitudes can be linked to past experiences and attitudes can be indicators for future behaviors. While some participants joined FFA in high school because of their advisor, other participants articulated dealing with an 
advisor they did not like was a reason for discontinuing their involvement after high school. Smith et al. (2007) stated that pre-college characteristics and experiences play a role in students' college experiences, and poor experiences with advisors could be indicators to why participants decided to discontinue with their involvement. Advisors play important roles on the high school level but are also involved with their local alumni chapters as well, influencing the FFA image. Further research should be conducted on the role of the FFA advisor in influencing involvement and retention of FFA members on all levels. Research could provide further insight and understanding on the positive and negative roles and influences advisors have on their students; as Greiman and Addington (2008) stated that agricultural teachers and advisors are seen as a major influence on students' personal leadership development. Future research should also be conducted on the advisor's role in FFA member burnout, and the reasons why FFA members experience burnout once they graduate high school. Participants noted that their advisors played a key role with their FFA experience, so further training and professional development for advisors should be considered in the areas of motivation and encouraging FFA involvement past high school, since advisors play a vital role in helping to make alumni chapters effective.

Ajzen (1991) stated that when resources and opportunities are made available to a person, the likelihood of behavioral achievement increases. Participants said during high school, they rarely heard about opportunities in the FFA past high school, if any at all. In relation to Ajzen's Theory of Planned Behavior (1991), members had little to no resources and opportunities available in high school, thus the behavioral achievement of joining Collegiate FFA and the FFA Alumni after high school was not achieved. If members heard about these opportunities, there was little detail about the opportunities, or they were informed of opportunities past high school by a visual presence at a state or national convention in the form of state officers, national officers, or booths at the career show. Further research should be conducted on the impacts of advertising on FFA involvement past high school. Since participants did not witness advertising about collegiate and alumni FFA opportunities, an evaluation of advertising efforts should be conducted to ensure the objectives and goals of local FFA Alumni chapter advertisings are being met. Participants expressed not every FFA member majors in agriculture in college, so main campus advertising could be beneficial to reach more members. Local FFA Alumni chapters on college campuses should consider advertising meetings, events, and FFA Alumni information on colleges' main campuses in addition to their agricultural campuses or common gathering areas, as many non-agriculture major participants had mixed perceptions of what Collegiate FFA and the FFA Alumni were. These mixed perceptions and unclear understandings could play a role in why FFA members discontinue their involvement.

Powell and Agnew (2007) found that collegiate student leaders are looking for opportunities to build their professional career network. Schumacher and Swan (1993) also found there is a high demand for leadership training on the collegiate level and our results concurred with both studies. Anderson and Kim (2009) stated that students place more importance on the areas they will receive more leadership development. Furthermore, Douglah (1970) found adults tend to be attracted to participate in activities that will satisfy their personal needs and provide opportunities. In this study, participants had less initiative to become involved in Collegiate FFA because there were not enough career advancing opportunities, especially for non-agricultural majors. Participants want to be involved in organizations that further their career and life goals. Further research should be conducted to see if and how local FFA Alumni chapters are making efforts to help members grow in career and skill development. Universities should consider evaluating their programs to see what career development opportunities are provided to members and where improvements can be made. Universities should consider hosting career and skill development events on main campuses instead of agricultural campuses in an effort to increase non-agriculture majors' involvement beyond high school.

Ajzen (1991) indicated that past behaviors and experiences could be indicators for future behaviors. In this case, participants had many incentives to join FFA in high school ranging from family influences, friends, advisors, and the chapter's reputation, which could be indicators of why they decided to not join Collegiate FFA or the FFA Alumni. Participants did not express anyone or anything to be an influence to join Collegiate FFA or the FFA Alumni and because of the lack of information regarding FFA opportunities past high school, participants had mixed perceptions of what being involved in Collegiate FFA or the FFA Alumni entailed. Thus, they were scared to join out of the fear of time commitment. We believe this might stem from the idea of no one preparing FFA members for involvement past high school, so members have nothing to base their involvement in collegiate or alumni FFA off of beside their high school experience. The local FFA Alumni chapter does not have a rigid programing structure, but participants did not know this, so they might base possible involvement off the high school structure, which is different on the alumni level. Change in practice should be considered to change FFA members' perceptions of what FFA Alumni involvement would entail. Agricultural educators should consider informing students about FFA opportunities past high school in the form of lessons, workshops, college visits, and at chapter meetings. The more information exposure FFA members receive, the more likely they are to be properly informed and not 
have as many misconceptions or lack of understanding about FFA opportunities past high school.

The National Research Council (2009) suggested that student participation in extracurricular activities could be more influential than formal instruction, especially during the career and life decision-making processes. Montelongo (2002) concurred; students need more opportunities to apply what they learn in the classroom to real world settings, increasing students' sense of intellectual, social, and emotional self. Furthermore, Allen et al. (2007) concluded that alumni of collegiate organizations stated their involvement with collegiate organizations had a great impact on their personal leadership development. Additionally, Crowther (2000) reaffirmed similar views with adult participation as participation can reaffirm learning and can contribute to social change. Similarly, participants said they liked applying what they learned in the classroom, but felt other organizations on their college campus were taking pieces of what FFA was in high school. Thus, participants felt they did not have enough time to be involved in those other organizations in addition to FFA. Croom and Flowers (2001a) suggested that the FFA needs to change the way it meets and satisfies members changing needs and interests. One possible way to do this is for the FFA Alumni to consider collaborating with other collegiate organizations that host competitions such as horse and poultry judging, debate teams, and so forth to provide college students the opportunities to participate in events they enjoyed in high school.

In summary, to increase FFA membership after high school, we recommend the National FFA consider implementing professional development to help advisors motivate and encourage their students to participate in FFA in high school and beyond (i.e., local FFA Alumni chapter). FFA chapters and advisors across the nation should examine their current communication efforts and determine if increased communication and advertising efforts in high school about FFA opportunities after high school are needed, so members are better informed before entering college and/or the workforce. Local alumni chapters on college campuses should consider advertising (i.e., flyers, booths, social media posts, emails) meetings, general information, and more on the main campus or common gathering places in addition to agricultural campuses to decrease the misconceptions related to FFA and increase participation from non-agricultural majors. Local alumni chapters on college campuses should also consider evaluating their programs to determine the types of career development opportunities that currently exist and seek to increase these opportunities from the suggested evaluation. What is more, alumni chapters on college campuses should consider hosting career development opportunities on main campuses or common gathering places to reach non-agricultural majors and possibly increase the priority of FFA in their lives. Additionally, the FFA Alumni should also consider increasing advertising efforts in local communities to raise awareness about the benefits of participation in the alumni organization. Since some participants stated there was no alumni chapter to return to, a call for action to increase the number of alumni chapters in Tennessee and possibly across the nation is needed. Moreover, the National FFA should consider publishing tips, training, and general information on how to start and maintain a successful alumni chapter in order to increase the number of alumni chapters across the country. Furthermore, as Collegiate FFA is no longer recognized as an official type of member by the National FFA Organization, FFA should consider how to engage students who are involved at the collegiate level and are transitioning to FFA Alumni.

Beyond the FFA, research should be conducted to determine how other youth development organizations, who have struggled to maintain membership or retain former members as supporters of their organization, have sought to address these issues and determine the transferability of the strategies used. Youth development organizations linked to technical careers may benefit from these insights. Additionally, research is warranted to document the types of educational experiences youth and adults of technical careers choose to participate in outside of the formal classroom, and the effects these experiences have on economic, career, health, and civic outcomes. Furthermore, adult organizations should consider researching reasons for participation, since adults also seek learning opportunities, a sense of belonging, and achievement outside of the workplace. Research outside the FFA could help increase adult participation in local communities but may also discover ways to satisfy individuals' fulfillment needs.

\section{References}

Ajzen, I. (1991). The theory of planned behavior. Organizational Behavior and Human Decision Processes. 179-211.

Allen, J., Ricketts, J. C., \& Priest, K. (2007). Contributions of pre-collegiate and collegiate leadership experiences to alumni leadership development. NACTA, 51(3), 56-61.

Anderson, J. C., \& Kim, E. (2009). Youth leadership development: Perceptions and preferences of urban students enrolled in a comprehensive agriculture program. Journal of Agriculture Education, 50(1), 8-20. https://doi.org/10.5032/jae .2009 .01008

Ary, D., Jacobs, L. C., Sorensen, C. K., \& Walker, D. A. (2014). Introduction to research in education edition (9th ed.). Belmont, CA: Wadsworth Cengage Learning.

Bandura. A. (1986). Social foundation of thought and action: A social cognitive theory. New York, NY: Prentice Hall. 
Berg, J. L. (2015). The role of personal purpose and personal goals in symbiotic visions. Frontiers in Psychology, 6, 443. https://doi.org/10.3389/fpsyg .2015 .00443

Bogdan, R. C. \& Biklen, S. K. (2007). Qualitative research for education. Boston, MA: Pearson Education, Inc.

Croom, D. B., \& Flowers, J. L. (2001a). Finding and keeping members: Perspectives of FFA members and non-members on the effectiveness of FFA programs and services. Proceedings of the 28th Annual National Agricultural Education Research Conference, New Orleans, LA, 72-84.

Croom, D. B., \& Flowers J. L. (2001b). A question of relevance: FFA programs and services as perceived by FFA members and non-members. Journal of Southern Agricultural Education Research, 51(1), 6-19.

Crowther, J. (2000). Participation in adult and community education: A discourse of diminishing returns. International Journal of Lifelong Education, 19(6), 479-492.

Denault, A. S., \& Poulin, F. J. (2009). Intensity and breadth of participation in organized activities during the adolescent years: Multiple associations with youth outcomes. Journal of Youth and Adolescence, 38(9), 1199-1213. https://doi.org/ 10.1007/s10964-009-9437-5

Dooley, K. (2007). Viewing agricultural education research through a qualitative lens. Journal of Agricultural Education, 48(4), 32-42. https://doi.org/10.5032/jae.2007.04032

Douglah, M. (1970). Some perspectives on the phenomenon of participation. Adult Education Quarterly, 88-98.

Feinstein, L., Bynner, J., \& Duckworth, K. (2006). Young people's leisure contexts and their relation to adult outcomes. Journal of Youth Studies, 305327.

Goecker, A. D., Smith E., Fernandez, J. M., Ali, R., \& Theller, G. R., (2015). Employment opportunities for college graduates in food, agriculture, renewable natural resources, and the environment. Retrieved from https://www.purdue .edu/usda/employment/

Greiman, B. C., \& Addington L. S. (2008). Youth leadership development self-efficacy. Journal of Leadership Education, 7(1), 1-23.

Grbich, C. (2007). Qualitative data analysis: An introduction. Thousand Oaks, CA: Sage Publications, Inc.

Lincoln, Y. S., \& Guba, E. G. (1985). Naturalistic inquiry. Beverly Hills, CA: Sage.

McNally, K. M., \& Harvey M. W. (2001). Career and technical student organizations: A perfect path to self-determination and successful transition. Preventing School Failure: Alternative Education for Children and Youth, 45(3), 114-118.

Montelongo, R. (2002). Student participation in college student organizations: A review of literature. Journal of the Indiana University Student Personnel Association, 2, 51-63.

National FFA Organization. (2015). About us. Retrieved from https://www.ffa.org/about/whatis-ffa

National FFA Organization. (2018a). Our membership. Retrieved from https://www.ffa.org/ourmembership/

National FFA Organization. (2018b). National constitution. Retrieved from https://ffa.app.box .com/s/m5882jaj17cxhn5kr971xl57nib4r5le

National Research Council (2009). Transforming agriculture education for a changing world.

Washington, DC: National Academies Press.

National Research Council. (2012). Education for life and work: Developing transferable knowledge and skills in the 21st century. Washington, DC: The National Academies Press.

Powell, D., \& Agnew, D. (2007). Student leader preferences: What students want from involvement in student organizations. NACTA Journal, 51(2), 11-18.

Ricketts, J., \& Rudd, J. (2004) Leadership development factors leading to the success of former Florida state FFA officers. Journal of Southern Agricultural Education Research, 54(1), 242-253.

Ricketts, J. C. (2005). The relationship between leadership development and critical thinking skills. Journal of Leadership Education 4(2), 2741.

Rosch, D. M., \& Coers, N. (2013). How are we educating agricultural students? A national profile of leadership capacities and involvement in college compared to non-agricultural peers. Journal of Agricultural Education, 54(1), 83-96. https://doi.org/10.5032/jae.2013.01083

Rossetti, R., McCaslin, N. L., \& Gliem, J. A. (1996). A National wide examination of FFA membership: Factors influencing students' decisions on whether or not to become members. Paper presented to the National FFA Board of Directors, Alexandria, VA.

Schumacher, L. G., \& Swan, M. K. (1993). Need for formal leadership training for students in a landgrant college of agriculture. Journal of Agricultural Education, 34(3), 1-9. https://doi.org /10.5032/jae.1993.03001

Smith, A. R., Garton, B. L., \& Kitchel, T. (2007). Secondary agricultural enrollment and FFA participation as predictors of collegiate academic success and retention. Proceedings of the 2007 American Association for Agriculture Education Research Conference, 34, 415-427.

Talbert, B. A., \& Balschweid, M. A. (2004). Engaging students in the agricultural education model: Factors affecting student participation in the 
national FFA organization. Journal of

Agricultural Education, 45(1), 29-41. https:// doi.org/10.5032/jae.2004.01029

Terenzini, P., \& Reason, R. (2005). Parsing the first year of college: A conceptual framework for studying college impacts. Proceedings of the annual meeting of Association for the Study of Higher Education, Philadelphia, PA

Tsang, S. K. M., Hui, E. K. P., \& Law, B. C. M. (2012). Self-Efficacy as a positive youth development construct: A conceptual review. The Scientific World Journal, 2012, 452327. https:// doi.org/10.1100/2012/452327

Wingenbach, G. J., \& Kahler, A. K. (1997). Selfperceived youth leadership and life skills of Iowa FFA members. Journal of Agricultural Education, 38(3), 1-10. https://doi.org/10.5032/jae.1997 .03018 